\title{
Inheritance of Resistance to Aflatoxin Production in the Cross Between Corn Inbreds B73 and LB31
}

\author{
K. W. Campbell, A. M. Hamblin, and D. G. White
}

First author: Monsanto Research Farm, RR 4, Monmouth, IL 61842-9804; and second and third authors: Department of Crop Sciences, University of Illinois, Urbana 61801.

Accepted for publication 7 August 1997.

\begin{abstract}
Campbell, K. W., Hamblin, A. M., and White, D. G. 1997. Inheritance of resistance to aflatoxin production in the cross between corn inbreds B73 and LB31. Phytopathology 87:1144-1147.

The inheritance of resistance to aflatoxin production in corn (Zea mays) caused by the fungus Aspergillus flavus was studied following inoculation in progeny derived from the cross between the susceptible inbred B73 and the resistant inbred LB31. In 1993, the susceptible parent B73 $\left(\mathrm{P}_{1}\right)$, resistant parent LB31 $\left(\mathrm{P}_{2}\right), \mathrm{F}_{1}, \mathrm{~F}_{3}$, and $\mathrm{BCP}_{1}$-selfed generations were evaluated. In 1994, the study was expanded to include the $\mathrm{F}_{2}, \mathrm{BCP}_{1}$, and $\mathrm{BCP}_{2}$ generations. Aflatoxin concentrations were higher in 1993 than 1994.

of the $F_{1}$ generation were significantly lower than the calculated midparent values, indicating dominant gene action favoring resistance. In 1994, values of the $F_{1}$ generation were not significantly lower than the calculated midparent value. The frequency distributions of aflatoxin values for families of the $\mathrm{F}_{3}$ and $\mathrm{BCP}_{1}$-selfed generations were skewed toward the resistant parent, also indicating dominance. Heritability based on a progeny mean basis of $\mathrm{F}_{3}$ families representing the additive variance plus one-fourth of the dominance variance was estimated at $66 \%$ over both years combined. Based on these results, selection for resistance to aflatoxin production in progeny derived from the cross between B73 and LB31 should be effective.
\end{abstract} Generation mean analysis showed that additive and dominant gene action were important for resistance to aflatoxin production. Potence ratios indicated dominance for resistance in both years. In 1993, aflatoxin values
Additional keywords: maize, mycotoxin.
Preharvest infection of corn kernels by Aspergillus flavus Link:Fr. causes ear and kernel rot, resulting in reduced grain quality and potential aflatoxin contamination of grain. Since the early 1970s, researchers have been evaluating corn germ plasm for resistance to aflatoxin production and Aspergillus ear rot $(2-4,7,9,10,13,15,18$, 20-23). Studies to determine the inheritance of resistance to aflatoxin production using diallel mating designs have shown general combining ability (suggesting additive gene effects) to be more important than specific combining ability (suggesting dominant gene effects) $(7,10,22,23)$. Diallel studies, in which the parents represent fixed genotypes (model I) instead of the parents being a random sample from a population (model II), are useful when information is desired regarding specific crosses and for all crosses involving a common parent. Inferences based on model I diallels, however, cannot be extended to the estimation of components of variance $(1,11)$.

Generation mean analysis has been used to study quantitatively inherited traits in corn including disease resistance $(3,5,6,12,17,19)$. It is useful for detecting the relative importance of genetic effects in a specific pair of lines (11). Generation mean analysis has several advantages compared with mating designs that are used for the estimation of genetic components of variance. Errors are inherently smaller when working with means (first order statistics) rather than variances (second order statistics), and smaller experiments are required to obtain the same level of precision (11). Additionally, populations evaluated in generation mean analysis provide generations that can be used in an applied breeding program.

Campbell and White (3) studied the inheritance of resistance to Aspergillus ear rot of crosses of nine resistant corn inbreds with the susceptible inbreds B73 and Mo17 following inoculation. Of the

Corresponding author: D. G. White; E-mail address: d-white@uiuc.edu

Publication no. P-1997-0929-01R

(C) 1997 The American Phytopathological Society inbreds evaluated, LB31 had consistently high levels of resistance to both Aspergillus ear rot and aflatoxin production. The inbred LB31 does not have commercially acceptable agronomic characteristics and is not currently used as a source of resistance to Aspergillus ear rot and aflatoxin production. Inbred lines related to B73 are widely used in commercial corn hybrids and are susceptible to Aspergillus ear rot and aflatoxin production. Therefore, studies on the types of gene action controlling resistance to both Aspergillus ear rot and aflatoxin production in a cross between B73 and LB31 would be useful in developing appropriate breeding procedures to transfer resistance from LB31 into commercially acceptable B73-related inbreds.

Inferences from our previous study apply only to ear rot, because Aspergillus ear rot and aflatoxin production were not highly correlated (Pearson's correlation coefficient $=0.49$ ) $(3)$. The poor relationship between ear rot and aflatoxin is further supported by restriction fragment length polymorphism (RFLP) mapping of the same $\mathrm{F}_{3}$ families from the B73 $\times$ LB31 cross (14). Three markers on three chromosomes $(2 \mathrm{~S}, 7 \mathrm{~L}$, and $9 \mathrm{~S})$ were significantly associated with ear rot resistance, and four markers on three chromosomes $(2 \mathrm{~S}, 2 \mathrm{~S}, 9 \mathrm{~L}$, and $10 \mathrm{~S})$ were associated with resistance to aflatoxin production. Only on chromosome $2 \mathrm{~S}$ were the same markers associated with resistance to both ear rot and aflatoxin production. Due to the poor relationships found between Aspergillus ear rot and aflatoxin production, it is necessary to determine the inheritance of resistance to aflatoxin production per se in addition to ear rot. The purpose of this study was to expand on previous work and determine the types and magnitude of gene action for resistance to aflatoxin production in the cross between $\mathrm{B} 73$ and LB31 using available seed of the $\mathrm{F}_{3}$ and $\mathrm{BCP}_{1}$-selfed generations from the previous study.

\section{MATERIALS AND METHODS}

In 1993, the $\mathrm{P}_{1}$ (B73), $\mathrm{P}_{2}$ (LB31), $\mathrm{F}_{1}, \mathrm{~F}_{3}$, and $\mathrm{BCP}_{1}$-selfed generations were evaluated. The $\mathrm{F}_{1}, \mathrm{~F}_{3}$, and $\mathrm{BCP}_{1}$-selfed generations were produced by crossing the parental inbred lines, selfing the $\mathrm{F}_{2}$ gen- 
eration, and selfing the $\mathrm{BCP}_{1}$ generation. The parental inbreds were planted adjacently within replications to prevent competition with more vigorous plants of the other generations. Plots were one row, 5.34-m long ( 24 plants/row), with a row spacing of $0.76 \mathrm{~m}$. A completely randomized design was used with six replications of the $\mathrm{P}_{1}, \mathrm{P}_{2}$, and $\mathrm{F}_{1}$ generations and with two replications of the $\mathrm{F}_{3}$ and $\mathrm{BCP}_{1}$-selfed generations. Each replication included two plots of the $\mathrm{P}_{1}, \mathrm{P}_{2}$, and $\mathrm{F}_{1}$ generations, 28 plots (families) of the $\mathrm{BCP}_{1}$-selfed generation, and 94 plots (families) of the $\mathrm{F}_{3}$ generation. Seed availability and labor required for inoculation and aflatoxin analysis did not allow for equal replication of each generation. More replications were used for the parents and $F_{1}$ generation to obtain a better estimate of the deviation of the $\mathrm{F}_{1}$ mean from the calculated midparent value.

In 1994 , the study was expanded to include the $\mathrm{F}_{2}, \mathrm{BCP}_{1}$, and $\mathrm{BCP}_{2}$ generations. The $\mathrm{F}_{2}$ generation was produced by selfing the $\mathrm{F}_{1}$ generation, and the $\mathrm{BCP}_{1}$ and $\mathrm{BCP}_{2}$ generations were produced by crossing $\mathrm{F}_{1}$ plants with $\mathrm{P}_{1}$ or $\mathrm{P}_{2}$ plants. Plot size and row spacing were the same as in the 1993 experiment. A completely randomized design was used with four replications of the $\mathrm{P}_{1}, \mathrm{P}_{2}, \mathrm{~F}_{1}$, $\mathrm{F}_{2}, \mathrm{BCP}_{1}$, and $\mathrm{BCP}_{2}$ generations and with three replications of the $\mathrm{F}_{3}$ and $\mathrm{BCP}_{1}$-selfed generations. Parental inbreds were planted adjacently as in 1993. Each replication included two plots of the $P_{1}$, $\mathrm{P}_{2}$, and $\mathrm{F}_{1}$ generations; seven plots of the $\mathrm{F}_{2}, \mathrm{BCP}_{1}$, and $\mathrm{BCP}_{2}$ generations; 28 plots (families) of the $\mathrm{BCP}_{1}$-selfed generation; and 98 plots (families) of the $\mathrm{F}_{3}$ generation. Experiments were planted 7 May 1993 and 17 May 1994 at the University of Illinois Agronomy/ Plant Pathology South Farm, Urbana.

Inoculum consisted of an equal mixture of conidia of four isolates of A. flavus. Three isolates $(6536,6539$, and 6540) were obtained from the Northern Regional Research Laboratory, Peoria, IL, and one was isolated from corn grain produced in Illinois in 1988. The isolates were selected based on high ear rot rating and aflatoxin production following inoculation in a 1990 virulence study (D. G. White, unpublished data). Inoculum was produced on potato dextrose agar in petri dishes incubated at $28^{\circ} \mathrm{C}$ with $12 \mathrm{~h}$ of light for 12 to 16 days. Cultures were blended with water and filtered through a double layer of cheesecloth. The resulting spore suspension was adjusted to $2 \times 10^{6}$ spores $/ \mathrm{ml}$ by dilution with distilled water, and two drops of Tween 20 per $100 \mathrm{ml}$ was added. Inoculum was prepared immediately before inoculation. Five milliliters of the spore suspension was injected through the husk leaves of the primary ear of each plant 20 to 24 days after midsilk using a pinboard inoculator (2). Plots were harvested 50 to 60 days after midsilk, and ears were dried in a forced-air dryer for 3 days. Ears from each plot were machine-shelled, and grain was bulked from each plot. Grain samples were ground with a Romer (model 2A; Romer Labs, Inc., Union, MO) grinding/subsampling mill to pass through a 1-mm screen, and a subsample of ground grain from each plot was analyzed for aflatoxin. Aflatoxin values of individual plots (rows) within replications were averaged for each generation.

Aflatoxin $\mathrm{B}_{1}$ in ground samples was determined using an indirect competitive enzyme-linked immunosorbent assay as previously described $(3,4)$. Samples were run in triplicate and averaged for each sample. The lower detection limit for aflatoxin $B_{1}$ using this protocol is $2 \mathrm{ng} / \mathrm{g}$.

Aflatoxin values were transformed using a natural log function to homogenize the variance. Samples with nondetectable aflatoxin were recorded as $2 \mathrm{ng} / \mathrm{g}$. Significance of deviations of the $F_{1}$ means from the calculated midparent values (the average of the two parents) were tested using $z$ values for the equality of the two population means within each year. Aflatoxin data for generation mean analysis were analyzed as a completely randomized design using the SAS GLM procedure (SAS Institute, Cary, NC). The data for generation mean analysis were analyzed for individual years, because of differences in replications and generations between years. Data were also analyzed over both years using the 1993 data and a reduced 1994 data set including the $\mathrm{P}_{1}, \mathrm{P}_{2}, \mathrm{~F}_{1}, \mathrm{~F}_{3}$, and $\mathrm{BCP}_{1}$-selfed generations, which represents only those generations that were com- parable over both years. The reduced and full 1994 data sets were compared using a chi-square test for homogeneity on the main effect mean squares and by observing the relative potence ratios, i.e., the ratio of the dominant to additive parameter estimates $(d / a)(16)$.

The significance of additive and dominant effects was tested by generation mean analysis of the unweighted log of the generation means. The model used in the analysis was

$$
\log Y_{k}=m+\alpha_{k} a+\beta_{k} d+e_{k}
$$

in which $\log Y_{k}=$ the $\log$-transformed mean of the $k$ th generation, $m=$ midparent value, $\alpha_{k}$ and $\beta_{k}$ are coefficients determined by the degree of genetic relationship of the $k$ th generation, $a=$ pooled additive effects, $d=$ pooled dominant effects, and $e=$ the pooled error. The coefficients for the genetic effect parameters were from Mather and Jinks (16). The model was fit using multiple regression.

Heritabilities were estimated on a progeny mean basis of $\mathrm{F}_{3}$ families by

$$
h^{2}=\sigma^{2}{ }_{{ }_{g} F_{3}} /\left[\left(\sigma_{p}^{2} / r e\right)+\left(\sigma_{g e}^{2} / e\right)+\sigma^{2}{ }_{g F_{3}}\right]
$$

in which $\sigma^{2}{ }_{g F_{3}}$ is the variance among $\mathrm{F}_{3}$ family means, $\sigma_{p}^{2}$ is the pooled error variance, $r$ is the number of replications, $e$ is the number of environments, and $\sigma_{g e}^{2}$ is the generation by environment variance (11). The variance among $F_{3}$ family means is equal to the additive variance plus one-fourth of the dominance variance (11). The SAS GLM procedure was used to obtain variance components for the effects of environments, replications within environments, families, and families by environments. All effects were considered random except the environment.

The sample sizes required to estimate the mean and variance of the $\mathrm{F}_{3}$ and $\mathrm{BCP}_{1}$-selfed populations were solved by

$$
n=\left(Z_{\alpha / 2}^{2} \sigma^{2}\right) / E^{2}
$$

in which $Z_{\alpha / 2}^{2}$ is the square of the $z$ score at $\alpha=0.05, \sigma^{2}$ is the population variance, and $E^{2}$ is the maximum error of estimation (8).

Average individual $\mathrm{F}_{3}$ and $\mathrm{BCP}_{1}$-selfed family means (nontransformed) of the families that were evaluated in both years were calculated for 1993 and 1994, and the average of the 2 years was used to produce frequency distributions. Classes were as follows: 0 to 20, 21 to 50,51 to 100,101 to 150,151 to 200,201 to 300,301 to 400 , and 401 to $500 \mathrm{ng} / \mathrm{g}$.

\section{RESULTS}

In 1993, mean aflatoxin values of generations ranged from $98 \mathrm{ng} / \mathrm{g}$ for LB31 to $367 \mathrm{ng} / \mathrm{g}$ for B73 (Table 1). In 1994, the dif-

TABLE 1. Aflatoxin means of various generations from the cross between B73 and LB31

\begin{tabular}{lcc}
\hline & \multicolumn{2}{c}{ Aflatoxin $(\mathrm{ng} / \mathrm{g})^{\mathrm{a}}$} \\
\cline { 2 - 3 } Generation & $1993^{\mathrm{b}}$ & $1994^{\mathrm{c}}$ \\
\hline $\mathrm{P}_{1}(\mathrm{~B} 73)$ & 367 & 133 \\
$\mathrm{BCP}_{1}$ & $\ldots^{\mathrm{d}}$ & 35 \\
$\mathrm{BCP}_{1}$-selfed & 56 & 74 \\
$\mathrm{~F}_{1}$ & 69 & 44 \\
$\mathrm{~F}_{2}$ & $\ldots$ & 39 \\
$\mathrm{~F}_{3}$ & 147 & 80 \\
$\mathrm{BCP}_{2}$ & $\ldots$ & 27 \\
$\mathrm{P}_{2}($ LB31) & 98 & 40 \\
Midparent & 233 & 87 \\
$\mathrm{~F}_{1}$-midparent & $-164^{\mathrm{e}}$ & -43 \\
\hline
\end{tabular}

a Measured by indirect competitive enzyme-linked immunosorbent assay. Samples were run in triplicate.

b Aflatoxin values in 1993 are means of six replications of the parental and $\mathrm{F}_{1}$ generations and two replications of the $\mathrm{BCP}_{1}$-selfed and $\mathrm{F}_{3}$ generations.

c Aflatoxin values in 1994 are means of four replications for the parental, $\mathrm{F}_{1}$, $\mathrm{F}_{2}, \mathrm{BCP}_{1}$, and $\mathrm{BCP}_{2}$ generations, and three replications for the $\mathrm{BCP}_{1}$-selfed and $\mathrm{F}_{3}$ generations.

d Generation was not evaluated.

Significant at probability level $P=0.001$. 
ference in aflatoxin values between LB31 (40 ng/g) and B73 (133 $\mathrm{ng} / \mathrm{g}$ ) was less. Aflatoxin values for most of the other generations also were lower in the second year, with mean aflatoxin values for the $F_{3}$ generation of $147 \mathrm{ng} / \mathrm{g}$ in 1993 and $80 \mathrm{ng} / \mathrm{g}$ in 1994 . Aflatoxin values of the $F_{1}$ generation were significantly lower than the calculated midparent values in $1993(P<0.001)$, but not in 1994 $(P>0.05)$.

Additive gene effects were significant $(\alpha=0.05)$ in $1993(P=$ $0.017)$, in $1994(P=0.016)$, and in the combined analysis $(P=$ 0.004) (Table 2). Dominant gene effects were not significant in 1993 at $P=0.091$ and were significant in 1994 at $P=0.025$ and combined over years at $P=0.013$. Residual mean squares from the additive-dominance model were not significant in any of the analyses. The year effect was not significant $(P=0.109)$ for the analysis of generation means. Generation $(\mathrm{G})$ by environment (E) (i.e., year) interactions over the 2 years of the study were not significant $(P=0.865)$. Heritability based on a progeny mean basis of $\mathrm{F}_{3}$ families, which represents the additive variance plus one-fourth of the dominance variance, was estimated at $66 \%$. The year effect in the analysis of $\mathrm{F}_{3}$ family means was significant at $P=0.088$ and the replication effect at $P=0.004$. The family by year interaction $(\mathrm{G} \times \mathrm{E})$ was significant at $P=0.070$.

The potence ratio, which is the ratio of dominant to additive parameter estimates $(d / a)$, in 1993 with five generations included was -1.20 . The potence ratio in 1994 was -1.76 with all generations included and -1.46 with the reduced data set of five generations. When the reduced data set from 1994 was combined with the 1993 data to provide a balanced analysis with five generations for each year, the potence ratio was -1.28 . All of the ratios of $d / a$ indicate dominance for resistance

The frequency distributions of aflatoxin values for the $F_{3}$ and $\mathrm{BCP}_{1}$-selfed families were skewed toward the resistant parent LB31 (Fig. 1). Most of the aflatoxin values of the $F_{3}$ families and all values of the $\mathrm{BCP}_{1}$-selfed families were lower than the susceptible parent $\mathrm{B} 73$. Based on the variance among the $\mathrm{F}_{3}$ families, a 95\% confidence level, and a maximum error of estimation of 23 ng/g, 208 families would be optimal in the estimation of the mean for this particular cross. The variance among the $\mathrm{BCP}_{1}$-selfed families, a 95\% confidence level, and a maximum error of estimation of $14.3 \mathrm{ng} / \mathrm{g}$ indicate that 52 families would be optimal in the estimation of the mean for this particular cross.

\section{DISCUSSION}

Both additive and dominant gene action were shown to be important in the inheritance of resistance to aflatoxin production in crosses between B73 and LB31. Generation mean analysis indicated significance for dominant gene action favoring resistance in 1994 and combined over years, but not in 1993. The increase from five generations in 1993 to eight generations in 1994 provided more

TABLE 2. Analysis of variance of mean log-transformed aflatoxin production for generations from the cross between B73 and LB31 evaluated in Urbana, IL, in 1993, 1994, and combined over years

\begin{tabular}{|c|c|c|c|c|c|c|}
\hline \multirow[b]{2}{*}{ Source } & \multicolumn{2}{|c|}{1993} & \multicolumn{2}{|c|}{1994} & \multicolumn{2}{|c|}{ 1994-1995 } \\
\hline & $\mathrm{df}^{\mathrm{a}}$ & $\mathrm{ms}^{\mathrm{b}}$ & df & $\mathrm{ms}$ & $\mathrm{df}$ & $\mathrm{ms}$ \\
\hline Environment (E) & $\cdots$ & & & & 1 & 1.85 \\
\hline Generation (G) & 4 & $5.27^{* \mathrm{c}}$ & 7 & 1.41 & 4 & $5.99 *$ \\
\hline Additive & 1 & $12.62 *$ & 1 & $4.38 *$ & 1 & $15.71 * *$ \\
\hline Dominance & 1 & 5.83 & 1 & $3.75^{*}$ & 1 & $8.24 * *$ \\
\hline Residual & 2 & 1.32 & 5 & 0.35 & 2 & 0.01 \\
\hline$G \times E$ & $\ldots$ & $\cdots$ & $\ldots$ & $\ldots$ & 4 & 0.46 \\
\hline Pooled error & 17 & 1.81 & 22 & 0.65 & 30 & 1.44 \\
\hline $\mathrm{CV}^{\mathrm{d}}$ & 30 & & 22 & & 28 & \\
\hline
\end{tabular}

${ }^{\mathrm{a}} \mathrm{df}=$ degrees of freedom.

${ }^{\mathrm{b}} \mathrm{ms}=$ mean squares.

c $*, * *=$ Significant at probability level $P=0.05$ and 0.01 ( $F$ test), respectively.

${ }^{\mathrm{d}} \mathrm{CV}=$ coefficient of variation degrees of freedom in the test for dominant effects, despite a decrease in variance among generation means and lower aflatoxin values in 1994. Dominance was more important in resistance to aflatoxin production than what was previously reported for ear rot resistance (3). Dominance also was indicated by the potence ratios and was suggested by a significant deviation of the $F_{1}$ mean from the midparent value in 1993. A decrease in the susceptible parent mean from 367 to $133 \mathrm{ng} / \mathrm{g}$ from 1993 to 1994 reduced the discrimination between resistant and susceptible parents. This reduced the midparent value from $233 \mathrm{ng} / \mathrm{g}$ in 1993 to $87 \mathrm{ng} / \mathrm{g}$ in 1994, which may have contributed to the lack of significant deviation of the calculated midparent value from the $F_{1}$ mean in 1994. In previous studies for ear rot, there were no significant differences of the $F_{1}$ mean from the midparent value (3). The greater importance of dominance for resistance to aflatoxin production than that previously found for ear rot resistance may be partially due to the greater magnitude of difference between aflatoxin values compared with ear rot ratings.
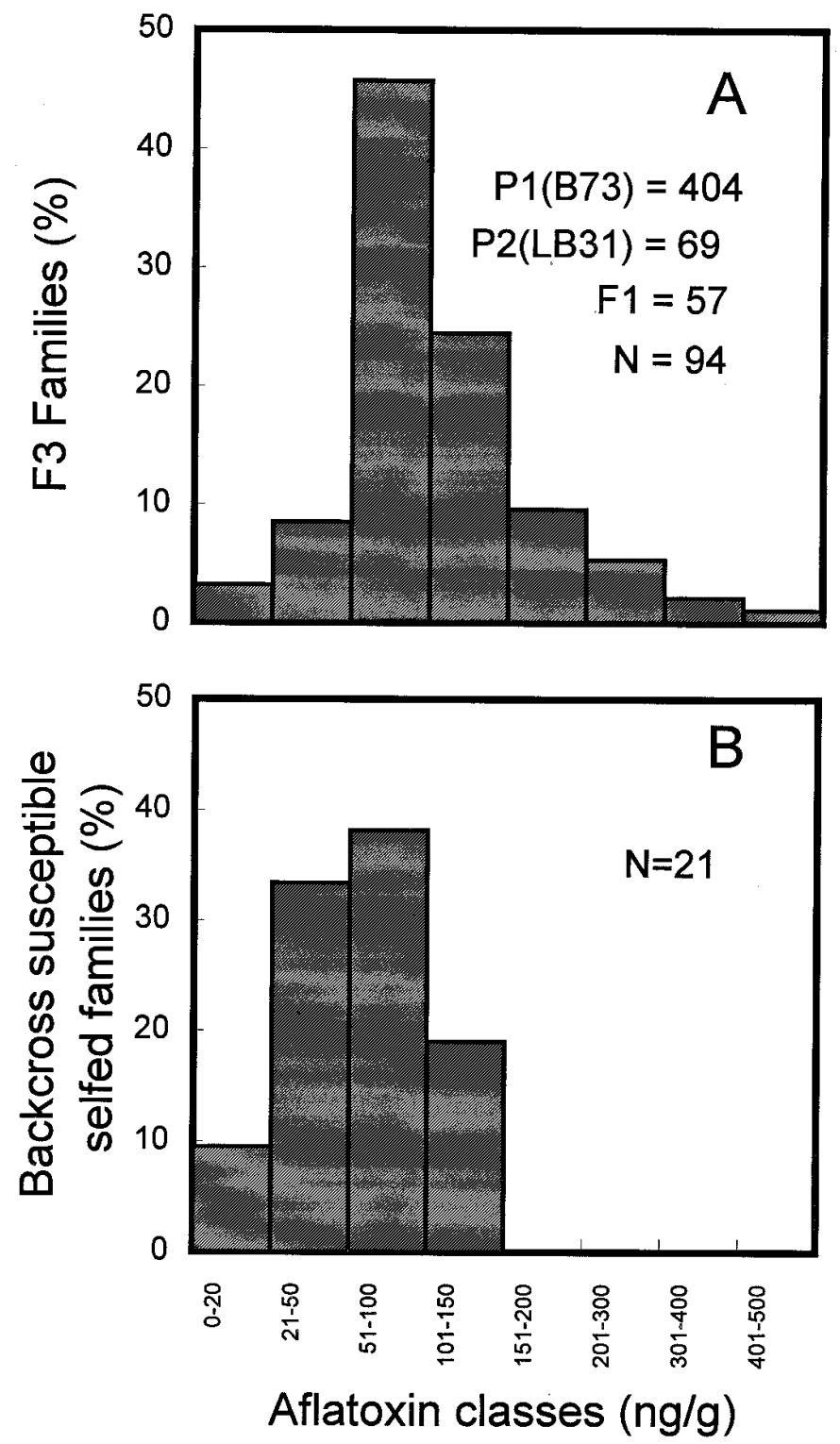

Fig. 1. Frequency distributions of aflatoxin means for $\mathbf{A}, \mathrm{F}_{3}$ families $\left(\mathrm{LSD}_{0.05}\right.$ $=155 \mathrm{ng} / \mathrm{g})$ and $\mathbf{B}, \mathrm{BCP}_{1}$-selfed families $\left(\mathrm{LSD}_{0.05}=94 \mathrm{ng} / \mathrm{g}\right)$ of the cross between B73 and LB31 evaluated in 1993 and 1994. The $F_{3}$ and BCP ${ }_{1}$-selfed families had two replications in 1993 and three replications in 1994. Parental and $F_{1}$ generation values are pooled aflatoxin means (ng/g) from 1993 (six replications) and 1994 (four replications). $\mathrm{N}=$ number of $\mathrm{F}_{3}$ or $\mathrm{BCP}_{1}$-selfed families. 
The frequency distributions of $\mathrm{F}_{3}$ and $\mathrm{BCP}_{1}$-selfed families, which are skewed toward the resistant parent LB31, also indicate dominance for resistance. It is interesting that none of the $\mathrm{BCP}_{1}$-selfed families were as susceptible as the susceptible parent. If a large number of loci were responsible for providing resistance in this cross, it is possible that a large sampling number would be required to observe samples in the $\mathrm{BCP}_{1}$-selfed generation that contain aflatoxin levels as high as the susceptible parent. In addition, the effect of bulking ears by row for toxin analysis may dilute the concentration of aflatoxin actually present in a small proportion of the susceptible plants.

This study includes more generations and total number of plants sampled than most previous studies on resistance to aflatoxin production in corn. In addition, this is one of the few attempts to study resistance to aflatoxin production using $\mathrm{F}_{3}$ and $\mathrm{BCP}_{1}$-selfed generations. Future evaluations may be directed more appropriately with respect to optimum sampling size for estimation of population means and variances for aflatoxin production. However, without the comparison of populations produced from crosses other than B73 $\times$ LB31, the optimal sampling sizes apply only to this specific cross.

A line development program was initiated in 1992 to develop inbred lines with high levels of resistance to Aspergillus ear rot and aflatoxin production. We currently have numerous lines in various stages of selfing and backcrossing developed using B73-related inbreds crossed with LB31. When grown in replicated trials, many of these genotypes have low levels of Aspergillus ear rot and aflatoxin. In our experience, the most common problem is the identification of a genetically susceptible line as being resistant. Usually, when these lines are evaluated the next year, their susceptibility becomes apparent. We would suggest that if resistance were to be crossed into B73-related inbreds, initial populations will need to be at least 200 families. A large number of susceptible families can be eliminated in those years that favor both Aspergillus ear rot and aflatoxin production. In those years that favor either ear rot or aflatoxin production, selection should only be concentrated on the phenotypic trait that offers the greatest spread in disease values. We have noticed with several different sources of resistance that in a year that favors both ear rot and toxin production as many as $80 \%$ of families can be eliminated because of susceptibility.

Because of the effect of environment, the quantitative nature of resistance, and the lack of correlation between aflatoxin production and Aspergillus ear rot, our goal is to use marker-assisted selection to greatly enhance the precision and speed of selection. With marker-assisted selection, selection could be made on the basis of RFLP markers in addition to ear rot and aflatoxin evaluation. A major advantage will be that families with different markers associated with resistance could be recombined. Marker-assisted selection also will be very useful in backcrossing resistance into agronomically acceptable inbreds and recovering the recurrent parent type.

\section{ACKNOWLEDGMENTS}

Research support provided by the USDA-CSRS grant AG-94-342150023 and grant AG-58-3620-0-003. We thank M. Lovekamp for her assistance in the aflatoxin assays.

\section{LITERATURE CITED}

1. Baker, R. J. 1978. Issues in diallel analysis. Crop Sci. 18:533-536.

2. Campbell, K. W., and White, D. G. 1994. An inoculation device to evaluate maize for resistance to ear rot and aflatoxin production by Aspergillus flavus. Plant Dis. 78:778-781.

3. Campbell, K. W., and White, D. G. 1995. Inheritance of resistance to Aspergillus ear rot and aflatoxin in corn genotypes. Phytopathology 85: 886-896.

4. Campbell, K. W., and White, D. G. 1995. Evaluation of corn genotypes for resistance to Aspergillus ear rot, kernel infection, and aflatoxin production. Plant Dis. 79:1039-1045.

5. Carson, M. L., and Hooker, A. L. 1981. Inheritance of resistance to anthracnose leaf blight in five inbred lines of corn. Phytopathology 71:488-491.

6. Carson, M. L., and Hooker, A. L. 1981. Inheritance of resistance to stalk rot of corn caused by Colletotrichum graminicola. Phytopathology 71:1190-1196.

7. Darrah, L. L., Lillehoj, E. B., Zuber, M. S., Scott, G. E., Thompson, D., West, D. R., Widstrom, N. W., and Fortnum, B. A. 1987. Inheritance of aflatoxin $\mathrm{B}_{1}$ levels in maize kernels under modified natural inoculation with Aspergillus flavus. Crop Sci. 27:869-872.

8. Freund, R. J., and Wilson, W. J. 1993. Statistical Methods. Academic Press, Inc., San Diego, CA.

9. Gardner, C. A. C., Darrah, L. L., Zuber, M. S., and Wallin, J. R. 1987. Genetic control of aflatoxin production in maize. Plant Dis. 71:426-429.

10. Gorman, D. P., Kang, M. S., Cleveland, T., and Hutchinson, R. L. 1992. Combining ability for resistance to field aflatoxin accumulation in maize grain. Plant Breed. 109:292-303.

11. Hallauer, A. R., and Miranda, J. B. 1988. Quantitative Genetics in Maize Breeding, 2nd ed. Iowa State University Press, Ames.

12. Hughes, G. R., and Hooker, A. L. 1971. Gene action conditioning resistance to Northern leaf blight in maize. Crop Sci. 11:180-184.

13. Kang, M. S., Lillehoj, E. B., and Widstrom, N. W. 1990. Field aflatoxin contamination of maize genotypes of broad genetic base. Euphytica 51: 19-23.

14. Kaufman, B., Campbell, K. W., White, D. G., and Rocheford, T. R. 1995. Maize RFLPs associated with resistance to fungal growth and aflatoxin production. Pages 174-175 in: Abstr. Annu. Meet. Am. Soc. Agron., 1995. American Society of Agronomy, Madison, WI.

15. Lillehoj, E. B., Kwolek, W. F., Vandegraft, E. E., Zuber, M. S., Calvert, O. H., Widstrom, N., Futrell, M. C., and Bockholt, A. J. 1975. Aflatoxin production in Aspergillus flavus inoculated ears of corn grown at diverse locations. Crop Sci. 15:267-270.

16. Mather, K., and Jinks, J. L. 1982. Biometrical Genetics, 3rd ed. Chapman and Hall Ltd., London.

17. Moll, R. H., Thompson, D. L., and Harvey, P. H. 1963. A quantitative genetic study of the inheritance of resistance to brown spot (Physoderma maydis) of corn. Crop Sci. 3:389-391.

18. Scott, G. E., and Zummo, N. 1988. Sources of resistance in maize to kernel infection by Aspergillus flavus in the field. Crop Sci. 28:504-507.

19. Toman, J., Jr., and White, D. G. 1993. Inheritance of resistance to anthracnose stalk rot of corn. Phytopathology 83:981-986.

20. Tucker, D. H., Jr., Trevathan, L. E., King, S. B., and Scott, G. E. 1986. Effect of four inoculation techniques on infection and aflatoxin concentration of resistant and susceptible corn hybrids inoculated with Aspergillus flavus. Phytopathology 76:290-293.

21. Widstrom, N. W., McMillian, W. W., and Wilson, D. M. 1987. Segregation for resistance to aflatoxin contamination among seeds on an ear of hybrid maize. Crop Sci. 27:961-963.

22. Widstrom, N. W., Wilson, D. M., and McMillian, W. W. 1984. Ear resistance of maize inbreds to field aflatoxin contamination. Crop Sci. 24: $1155-1157$.

23. Zuber, M. S., Calvert, O. H., Kwolek, W. F., Lillehoj, E. B., and Kang, M. S. 1978. Aflatoxin $\mathrm{B}_{1}$ production in an eight-line diallel of Zea mays infected with Aspergillus flavus. Phytopathology 68:1346-1349. 